\title{
CULTISMOS EN LA GERMANÍA DEL SIGLO XVII
}

A partir de su $15^{\text {a }}$ edición (1925), el Dicc. Acad. registra el vocablo de germanía alatés, que significa 'criado de un rufián o ladrón'. No figura esta palabra, que yo sepa, en diccionario español alguno de fecha anterior. Como no tiene uso en la lengua moderna, es de suponer que para darle acogida en la edición mencionada, y también en su Diccionario histórico (1933), la Academia se basó en la única autoridad de un pasaje del Estebanillo González, que dice así: "Descubrióme, por habérsele ido un alatés suyo, el modo de su gandaya, el provecho que sacaba della y de la suerte que disponía su enredo; pidióme que le ayudase. Prometióme el tercio de lo que se adquería, después de pagados los gastos" (ed. J. Millé y Giménez, en Clás. cast., vol. I, pág. 167). Aunque nada se ha dicho acerca del origen de alatés, es evidente que se trata de una deformación de la expresión latina a latere; es decir, un cultismo más o menos extendido o popularizado en el habla de germanía. Encontramos el latinismo a latere usado burlescamente en el Corbacho: “... E con esto es ella tanto mirada; pues nin grado nin gracias synon a los alateres de quien salió tal fermosura" (ed. Biblióf. esp., págs. 136-137). Al popularizarse debió de cambiar el acento.

En mis exploraciones léxicas no he podido dar con otros ejemplos de alatés, fuera del texto del Estebanillo citado por la Academia. Su empleo no debió de ser muy extenso, por lo menos en la lengua escrita. Pero su evidente origen docto conduce a algunas reflexiones generales sobre el cultismo como factor operante en la formación del habla de germanía.

En su excelente Estudio sobre los gitanismos del español (Madrid, 1951, págs. 16-19), Carlos Clavería dice con acierto que la germanía no se ha estudiado rigurosamente. Nada o casi nada sabemos, en efecto, sobre la procedencia del copioso vocabulario característico del hampa delincuente durante el siglo xvII, que es cuando la denominación de germania tiene pleno sentido. Desde el siglo xviI -dice Clavería - la confusión entre germania, o lenguaje especial de los delincuentes profesionales, y el caló, o lengua de los gitanos españoles de remoto origen indio, debió de ser corriente en España. Tan corriente ha sido esa confusión, que aún hoy la Academia no emplea más denominación que la de germanía para todos los 
vocablos o expresiones que respondan más o menos al concepto que en otros países se conoce con los nombres de argot, slang, cant, gergo, etc. Es característica universal de la jerga delincuente la necesidad de renovarse constantemente, a fin de-que no se divulgue entre los profanos y quede inutilizada como "lenguaje de ocultación", según la llamó Jespersen ${ }^{1}$. Los hampones sevillanos de comienzos del siglo xvir conocían bien esta necesidad de cambiar su léxico:

Habla nueva germanía, porque no sea descornado; que la otra era muy vieja, y la entrevan los villanos ${ }^{2}$.

Falta, pues, un estudio científico de esta germanía nueva del siglo XVII, especialmente en su primera mitad, antes de que la invadieran, renovándola otra vez, abundantes elementos léxicos de procedencia gitana. En las palabras germanescas conservadas en los textos es fácil reconocer en seguida algunos procedimientos formativos propios de estos lenguajes de ocultación en todos los países, como por ejemplo las transposiciones de consonantes (chepo, greno, taplo, por 'pecho', 'negro', 'plato'), metáforas burlescas (gabia = 'casco', las once mil virgenes = 'la cota de malla'), extranjerismos (como el arabismo gurapas por 'galeras'), etc., etc. Pero fuera de estas indicaciones generales, son muy pocos nuestros conocimientos seguros sobre el origen de las voces de germanía. A fin de contribuir a un futuro estudio de conjunto, que alguien emprenderá algún día, quiero en estas notas señalar una parcelà de vivo interés lingüístico y social.

Repasando el Vocabulario de germanía de Cristóbal de Chaves, impreso en Barcelona a nombre de Juan Hidalgo el año 1609 , el lector moderno se sorprende por la relativa abundancia de palabras cultas que en él están recogidas, verdaderos latinismos de forma y de concepto que no se esperarían en el lenguaje de pícaros y hampones $^{3}$. He aquí los ejemplos más claros:

De a 1 b u s 'blanco': alba 'sábana'; albanado 'dormido'; albaneses 'dados de jugar'; albanesero, albanejero y albaneguero 'jugador de dados'; albaire 'huevo'.

De c a l c e u: calca 'camino'; calcar 'caminar, andar'; calco 'acción de andar, pisar, pisada'; calcorrear y calcotear 'correr'; calcoteado 'corrido'; calcorros 'zapatos'.

${ }^{1}$ Humanidad, nación, individuo, desde el punto de vista lingüistico. Trad. de F. Vela, Buenos Aires, 1947, págs. 189 y sigs.

${ }^{2}$ Romance $3^{\text {o }}$ de los publicados a nombre de Juan Hidalgo. Véase Rafael Salillas, "Poesía rufianesca (jácaras y bailes)" en $R H i$, XIII, 1905.

${ }^{3}$ Además de la edición citada, me he servido de J. M. Hill, Poesias germanescas, Bloomington, 1945, y Voces germanescas, Bloomington, 1949. Cf. también la reseña de Clavería en $H R$, XVI, 1948, págs. 47 y sigs. 
Certus, usado así en latín, era el cierto, 'fullero o avisador del fullero'.

Finibusterre: 'Ia horca'.

De lo ng u s: peñas de longares 'alejarse, irse muy lejos'; longares y longuiso 'hombre que huye, que se aleja, cobarde'.

De l u d us: ludios 'cuartos u ochavos para jugar'.

De potus: potar 'beber'; potado 'borracho'.

Similerates o similerrates, 'ladroncillos temerosos'. Aparece también la variante similirrates.

En algunos casos, tales palabras presentan alteraciones debidas a la pronunciación popular, lo cual nos garantiza su uso efectivo en la lengua hablada; por ejemplo, carcamo 'camino' (cf. calca y calcar mencionados antes), con la $l$ final de sílaba convertida en $r$. Entre estas deformaciones, en que a veces intervienen la etimología popular y la analogía, recordemos el nombre del personaje cervantino Monipodio (<monopolio) y su afición a valerse de expresiones sabias, como naufragio por 'sufragio', estupendo por 'estipendio' y otros graciosos disparates hipercultos, a tono con su autoridad de presidente de la cofradía de ladrones. Otras veces se trata del empleo de metáforas o conceptos de evidente procedencia docta: Sagitario 'el que llevan azotando por las calles montado en un burro'; Babilonia 'Sevilla'; Tramontanas y Trassilvanas 'los arrabales en que vivía la gente del hampa' 4 ; lucerna 'candela'; lucerno 'candelero'; salterio 'salteador'.

Rodriguez Marín ${ }^{5}$ y Hazañas y la Rúa ${ }^{6}$ nos dan noticia de numerosas frases latinas usadas en la jacarandina sevillana. Por ejemplo, aetatem mahometicam o los años de Mahoma, era el número 48 para los tahures, es decir $4^{8}$ puntos en el juego ${ }^{7}$; con la frase semper rogati ganant procuraban convencer al que se resistía a jugar; al que estaba de pérdida le cantaban el salmo Conserva me Domine. La mesa en que se jugaba al parar se llamaba tabla de majoribus. Llamaban irreverentemente a los que iban a entrar a jugar con la frase eclesiástica accedant qui ordinandi sunt ${ }^{8}$.

Antes de admitir como usuales en el habla germanesca tales palabras o expresiones, conviene, sin embargo, someterlas una por una a crítica rigurosa. Nótese que los romances y otros versos de germanía fueron compuestos casi siempre por autores instruídos y a me-

4 A. Bonilla, "La vida del pícaro", en $R H i$, IX, 19o2, págs. 295-330.

"El Loaysa de "El celoso extremeño", Sevilla, 19o1; véase también, y muy especialmente, su introducción a Rinconete y Cortadillo, Sevilla, 1906.

- Estudio preliminar a Los rufianes de Cervantes, Madrid, 19o6.

- En su Marcos de Obrégón Espinel refiere una anécdota sobre la expresión "los años de Mahoma" entre los jugadores (Rel. II, Desc. 6).

${ }^{8}$ Estas frases latinas, y algunas más, se hallan en el libro de J. Hazañas citado en la nota 6 (págs. $4^{0-5}$ ). 
nudo de gran renombre (Góngora, Quevedo), los cuales escribían con intención irónica o caricaturesca, y es natural que con las palabras auténticas del hampa mezclasen ocurrencias o metáforas propias, a fin de aumentar la comicidad. El mismo Cristóbal de Chaves, verdadero autor de los Romances de germania y del Vocabulario que desde 1609 corre a nombre de Juan Hidalgo, era hombre letrado, según demostró Rodríguez Marín ${ }^{9}$. En este sentido, por ejemplo, me parece inventada por el autor la expresión yegua de Neptuno 'galera' que hallamos en un romance ${ }^{10}$. Pero hechas todas las salvedades necesarias y después de someter caso por caso a precavido examen, quedan siempre muchos vocablos cuyo origen culto necesita explicación.

Aunque son siempre borrosos los límites que separan las hablas jergales de las zonas vulgar y familiar de la lengua común, la relativa abundancia de voces doctas que debieron de ser introducidas entre los maleantes por personas que tuvieran por lo menos algunas nociones de latín, hace pensar, por un lado, en el grupo profesional de la administración de justicia: jueces, escribanos, procuradores, alguaciles, etc., cuyos tecnicismos pudieron propagarse entre los pobladores de las cárceles. Es bien sabido el profundo conocimiento que los delincuentes habituales tienen del código penal, y con qué precisión manejan términos de derecho como dolo, alevosia, ate nuante, eximente, etc. A la terminología jurídica pertenece seguramente la denominación de censuaria 'manceba que contribuye con su ganancia al rufián', que hallamos atestiguada en nuestras fuentes como usual en la'germanía del siglo xvir. Por otra parte, el vocabulario eclesiástico da su aportación, no sólo a la germanía ${ }^{11}$, sino también a la lengua común; recordemos las frases latinas anteriormente citadas; el nombre Noli me tangere que los pícaros aplicaban al juez, y el de maniqueos que daban a los prestamistas en las casas de juego. Pero más importantes por su número y arraigo en la germanía

9 Introducción a Rinconete y Cortadillo, Sevilla, 1906.

10 J. M. HILL, Voces germanescas, s. v. yegua.

12 Wartburg, $F E W$, s. v. artos, habla de la palabra arton 'pan', documentada en el argot francés en el siglo Xvi, a la cual atribuye origen griego, considerándola como vocablo eclesiástico que designaba el 'pan para ofrendas'. Añade que no puede sorprender a los conocedores del argot que una palabra eclesiástica se haya extendido en los medios profanos. Los datos de la germanía española confirman lo que dice Wartburg sobre la propagación de voces ecle. siásticas como tesis general. Por lo que se refiere a la palabra artón, es curioso observar que existió también en nuestra germania con esta misma grafía y con la de hartón, que hace pensar en un cruce con hartón, de hartar, suponiendo que sea cierto el origen griego del vocablo. No estará de más advertir que esta voz se encuentra también en vasco (Azkue), donde significa 'mijo', 'maíz' y 'pan'. Fuera del país vasco, perteneció al argot, tanto en Francia como en España. Parece, pues, que habría que revisar la cuestión de origen, a base de la cronología de los textos en que aparece artón en ambos países, cosa que por ahora no me es posible hacer. 
son, a mi modo de ver, los vocablos nacidos en el ambiente escolar apicarado de las universidades.

Carecemos de noticias directas sobre la existencia de una jerga escolar en Salamanca, Alcalá y otros estudios menos célebres. Es fácil suponerla, sin embargo, por algunos indicios, y sobre todo por la intensa vida corporativa que tuvieron, favorable en todos los tiempos para que se desarrolle un léxico profesional dentro de la lengua común. Las descripciones que nos han dejado Mateo Alemán, Espinel, Quevedo y otros escritores, no dejan lugar a dudas sobre la atmósfera maleante de los principales centros universitarios: estafas, robos, pendencias y estocadas; estudiantes que ejercen de rufianes en las mancebías; conflictos repetidos por estas causas, entre la jurisdicción de los rectores y las autoridades civiles. Con frecuencia, no es ya el ambiente de bromas juveniles más o menos pesadas, sino de escándalos y aun verdaderos delitos que a veces tomaron proporciones de batalla en los famosos rencuentros de estudiantes armados con la ronda nocturna. En el Marcos de Obregón se habla (Rel. I, Desc. 14) de las algaradas estudiantiles que se produjeron en Salamanca el año 1572 , con motivo del proceso de fray Luis de León, y de la dispersión de estudiantes crdenada por el corregidor don Enrique de Bolaños. Muchos eran los escolares que por afán aventurero se hacían soldados e iban a Italia o a Flandes; otros abandonaban los estudios para hacerse valentones o fulleros profesionales, y en esta constante interpenetración entre los medios estudiantiles y el hampa delincuente ha de encontrarse la explicación de una gran parte de los cultismos propagados en la germanía.

Cervantes nos pinta en el primer capítulo de La ilustre fregona un muchacho de rica e hidalga familia burgalesa, que abandonó los estudios para vivir como picaro en las almadrabas del duque de Medina, que eran, como él dice, el Finibusterre de la picaresca, y "él salió tan bien con el asumpto de pícaro, que pudiera leer cátedra en la Facultad al famoso de Alfarache". El Loaysa del Celoso extre. meño parece inspirado, según Rodríguez Marín, en el modelo vivo de un-joven instruído y algo poeta que se dió a la bravuconería maleante y acabó en la horca, después de haber sido largo tiempo el terror de los alguaciles de Sevilla. No importa aquí dilucidar si hay que dar como buena la identificación entre el personaje cervantino y su pretendido modelo real. Lo importante para nosotros es percatarnos de que tales recuerdos literarios no son un mero capricho de los escritores, sino el reflejo evidente de una realidad social que hacía frecuente la entrada de estudiantes en el hampa, y con ella el trasvasamiento de vocablos doctos al lẹguaje de germanía.

Madrid.

Samuel Gili Gaya 